\title{
Mortality due to cardiovascular diseases in the Americas by region, 2000-2009
}

Mortalidade por doenças cardiovasculares nas Américas segundo região, 2000-2009

\author{
Vilma Pinheiro Gawryszewski', Maria de Fatima Marinho de Souza" \\ Communicable Diseases and Health Analysis, Pan-American Health Organization, World Health Organization, Washington, United States
}

'MD, MSc, PhD. Advisor, Health Information and Analysis, Health Information and Analysis Unit,

Pan-American Health Organization, Washington DC, United States.

"MD, MSc, PhD. Advisor, Regional Health

Observatory, Pan-American Health Organization.

\section{KEY WORDS:}

Mortality.

Cardiovascular disease.

Trends [subheading].

Inequality.

Americas.

\section{PALAVRAS-CHAVE:}

Mortalidade.

Doenças cardiovasculares.

/tendências.

Desigualdades em saúde

Américas.

\begin{abstract}
CONTEXT AND OBJECTIVE: Cardiovascular diseases are the leading cause of death worldwide. The aim here was to evaluate trends in mortality due to cardiovascular diseases in three different regions of the Americas.

DESIGN AND SETTING: This was a time series study in which mortality data from three different regions in the Americas from 2000 to the latest year available were analyzed.

METHODS: The source of data was the Mortality Information System of the Pan-American Health Organization (PAHO). Data from 27 countries were included. Joinpoint regression analysis was used to analyze trends.

RESULTS: During the study period, the age-adjusted mortality rates for men were higher than those of females in all regions. North America (NA) showed lower rates than Latin America countries (LAC) and the Non-Latin Caribbean (NLC). Premature deaths (30-69 years old) accounted for $22.8 \%$ of all deaths in NA, 38.0\% in LAC and $41.8 \%$ in NLC. The trend analysis also showed a significant decline in the three regions. NA accumulated the largest decline. The average annual percentage change (AAPC) and 95\% confidence interval was -3.9\% $[-4.2 ;-3.7]$ in NA; $-1.8 \%[-2.2 ;-1.5]$ in LAC; and - $1.8 \%[-2.7 ;-0.9]$ in NLC.

CONCLUSION: Different mortality rates and reductions were observed among the three regions.
\end{abstract}

\section{RESUMO}

CONTEXTO E OBJETIVO: As doenças cardiovasculares são as causas principais de morte em todo o mundo. O objetivo do estudo foi avaliar as tendências na mortalidade decorrente das doenças cardiovasculares em três diferentes regiões das Américas.

TIPO DE ESTUDO E LOCAL: Este é um estudo de série temporal que analisa dados de mortalidade em três diferentes regiões das Américas, de 2000 até o último ano disponível.

MÉTODOS: A fonte de dados foi a Sistema de Informação de Mortalidade da Organização Pan-Americana da Saúde (OPAS). Dados de 27 países foram incluídos. Utilizou-se joinpoint regression para analisar as tendências.

RESULTADOS: Durante o período de estudo, as taxas ajustadas por idade padronizadas de mortalidade dos homens foram mais altas que a das mulheres em todas as regiões. As taxas da América do Norte (AN) foram inferiores que as dos países da América Latina (AL) e do Caribe Não Latino (CNL). As mortes prematuras (30-69 anos) foram 22,8\% do total de mortes na AN, 38,0\% na AL e 41,8\% no CNL. A análise das tendências mostrou diminuição significativa nas três regiões. A AN acumulou a maior diminuição. A porcentagem média de mudança anual (AAPC) e respectivos intervalos de confiança de $95 \%$ foram $-3,9 \%[-4,2 ;-3,7]$ na AN; na AL foi - $1.8 \%[-2.2 ;-1.5]$; e - $1,8 \%[-2,7 ;-0,9]$ no CNL.

CONCLUSÕES: Foram observadas diferentes taxas de mortalidade e diferentes reduções nas três regiões. 


\section{INTRODUCTION}

Cardiovascular diseases (CVDs) are the leading cause of death worldwide, accounting for $30 \%$ of the total number of annual deaths globally. ${ }^{1}$ They comprise major disorders of the heart and blood vessels, which include heart coronary disease and stroke. Nowadays, this group of diseases is not considered to be only a problem of developed countries, since estimates for 2010 showed that low and middle-income countries were more affected, since they accounted for $80 \%$ of these deaths. ${ }^{1}$

Globally, ageing and unhealthy behavioral changes like tobacco smoking, physical inactivity and unhealthy diets, have become important contributors to the increased prevalence of intermediate risk factors such as obesity, dyslipidemia, raised blood pressure and raised blood sugar. Age is an unavoidable risk factor, but avoidance of premature mortality should be a public health concern; the percentage of premature deaths ranges from $4 \%$ in high income countries to $42 \%$ in lowincome countries. ${ }^{2}$

This group of diseases is important to public health not only because of their magnitude but also because of the possibility of intervention. Prevention strategies at population level to reduce circulatory system mortality rates can be classified as high-risk and community-based. ${ }^{3}$ The first of these relates to identifying individuals who are at high risk, through screening, and referring them for treatment. The second of these comprises implementation of programs at population level aimed at modifying one or more scientifically well established risk factors such as use of tobacco, physical inactivity, etc. As a result of implementation of such programs and policies, declines in mortality due to CVDs have been documented, mainly in developed countries but also in some Latin America countries. ${ }^{4-8}$

Socioeconomic indicators have been associated with differences in mortality, incidence and prevalence of cardiovascular risk factors, ${ }^{1,7-8}$ and considerable disparities among countries in the Americas regarding CVD death rates have also been found. ${ }^{8}$

\section{OBJECTIVE}

The objective of this study was to evaluate trends in mortality due to CVD in three different regions of the Americas.

\section{METHODS}

\section{Case definition and source of data}

Data were obtained from the Mortality Information System (updated in August 2012), which comprises mortality databases provided to the Pan-American Health Organization (PAHO) by the countries in the Americas. To ensure comparability among countries with different qualities of information, we used the data corrected for under-reporting and ill-defined deaths, in accordance with published methodology. ${ }^{9}$ This study included all the deaths for which the underlying cause of mortality was coded in Chapter IX, Diseases of the Circulatory System (I00-I99), of the International Statistical Classification of Diseases and Related Health Problems, Tenth Revision (ICD-10). Premature mortality was defined as deaths that occurred among people aged 30-69 years old. For this definition, the life expectancy in the countries of the region of the Americas ${ }^{10}$ and a publication from the World Health Organization (WHO $)^{11}$ were taken into account.

The criterion for including countries in this study was that they needed to have a time series available for the study period. The countries were distributed geographically into three regions: 1) North America (2 countries): Canada and the United States; 2) Latin America (13 countries): Argentina, Brazil, Chile, Colombia, Costa Rica, Ecuador, El Salvador, Mexico, Nicaragua, Panama, Paraguay, Peru and Venezuela; 3) Non-Latin Caribbean countries (12 countries): Antigua \& Barbuda, Aruba, Belize, Bermuda, Guyana, Montserrat, Saint Kitts \& Nevis, Saint Vincent and the Grenadines, Suriname, Trinidad \& Tobago, Turks \& Caicos Islands and Virgin Islands (US). In addition to geographical location, these sub-regions have some economic, social and cultural similarity. The period of study included data from 2000 to the latest available year (LAY). For North America and Latin America, the LAY was 2009, and for the Non-Latin Caribbean it was 2008.

Age-adjusted rates were calculated using estimates from the United Nations Population Division ${ }^{12}$ and the WHO Standard Population ${ }^{13}$ (direct standardization). This study analyzed anonymous secondary data on mortality and therefore no ethics approval was required.

\section{Data analysis}

This was a time-series study. We began with a descriptive analysis on $16,940,728$ deaths due to CVD registered in the system, focusing on sex, age, sub-region of residence and year of occurrence. To explain the trend patterns, a subsequent analysis was performed using the Joinpoint Regression Program, version 4.0.1 (January 2013), from the National Cancer Institute (http://surveillance.cancer.gov/joinpoint/). The dependent variable was the age-adjusted rates and the independent variable was the year. This software identified points at which the slope of the linear trend changed significantly, ${ }^{5}$ by using the age-adjusted rates from 2000 to LAY to fit a regression line to the natural logarithm of the rates. It calculated the average annual percentage change (AAPC), which is a summary measurement of the trend over a fixed time period, taking into account the trend transitions. ${ }^{14}$ The AAPC was considered to be significant when the slope was different from "zero" at alpha $=0.05$. The significance tests used a Monte Carlo permutation method. 


\section{RESULTS}

During the study period, in all the countries included in the study, females accounted for $51.0 \%$ and males for $49.0 \%$ of all CVD deaths. Table 1 presents some descriptive characteristics of this mortality in each region. The highest annual average of deaths was seen in North America, where almost one million deaths occurred annually (55.3\% overall), followed by Latin America (around 800,000 deaths; $44.3 \%$ overall) and then Non-Latin Caribbean (around 7,500 deaths; $0.4 \%$ overall). The proportion of premature mortality varied widely regarding sex and region. Males showed a higher proportion of premature mortality in all sub-regions, compared with females. North America presented the lowest proportion of premature deaths $(22.8 \%$ overall; $14.6 \%$ among females and $31.8 \%$ among males), in comparison with the other subregions. In Latin America, these percentages were: 38.0\% overall; $31.3 \%$ among females and $44.3 \%$ among males. In the Non-Latin Caribbean countries, almost half of one percent of the deaths due to circulatory system diseases were considered to be premature $(41.8 \%$ overall; $36.0 \%$ among females and $46.9 \%$ among males).

Although the average number of deaths was greater among females, the age-adjusted rates were not. In all regions, the rate among males was higher than the rate among female. Although the average number of deaths was greater in North America, the age-adjusted rates were not. Both in 2000 and LAY, the North American selected countries presented lower age-adjusted rates than the Latin American selected countries and Non-Latin Caribbean selected countries. Using the mortality rates for the latest year available, the risk of dying due to a CVD presented by a person who lived in the Non-Latin Caribbean region was 1.9 times the risk presented by a person who lived in the North American region.

\section{Trend analysis}

The results from the trend analysis (Table 1 and Figures 1, 2 and 3) showed that CVD mortality has declined in the three regions of the Americas. In North America, the overall ageadjusted rates per 100,000 dropped from 192.3 in 2000 to 135.5 in 2009 , a decrease of $29.5 \%$. The rates were higher among males but the decrease was greater among females. In Latin America, mortality has also been declining: the overall ageadjusted rates per 100,000 dropped from 229.9 in 2000 to 191.4 in 2009 , a decrease of $14.1 \%$. Compared with North America, the rates were higher and the decrease was smaller. In the NonLatin Caribbean Region the adjusted rates per 100,000 dropped from 296.4 in 2000 to 264.1 in 2008 , a decrease of $10.9 \%$. The percentage decline was lower than in North America and Latin America. Although this region showed the smallest number of
Table 1. Mortality due to cardiovascular diseases (ICD-10 I00-199) according to sex and region. North America, Latin America and Non-Latin Caribbean, 2000-LAY

\begin{tabular}{|c|c|c|c|}
\hline & North America & Latin America & Non-Latin Caribbean \\
\hline \multicolumn{4}{|c|}{ Deaths/year (average) } \\
\hline Female & 491,475 & 366,302 & 3,535 \\
\hline Male & 445,775 & 383,784 & 3,952 \\
\hline Total & 937,249 & 750,086 & 7,486 \\
\hline \multicolumn{4}{|c|}{$\%$ proportion of deaths $30-69$} \\
\hline Female & 14.6 & 31.3 & 36.0 \\
\hline Male & 31.8 & 44.3 & 46.9 \\
\hline Total & 22.8 & 38.0 & 41.8 \\
\hline
\end{tabular}

Age-adjusted rates $/ 100,000$

2000

$\begin{array}{cccc}\text { Female } & 159.9 & 193.4 & 243.3 \\ \text { Male } & 229.9 & 257.6 & 366.7 \\ \text { Total } & 192.3 & 222.9 & 296.4 \\ \text { LAY } & & & \\ \text { Female } & 109.3 & 163.1 & 216.4 \\ \text { Male } & 165.8 & 224.9 & 325.1 \\ \text { Total } & 135.5 & 191.4 & 264.1\end{array}$

$\%$ of change 2000-LAY

$\begin{array}{llll}\text { Female } & -31.6 \% & -15.6 \% & -11.0 \% \\ \text { Male } & -27.8 \% & -12.7 \% & -11.3 \% \\ \text { Total } & -29.5 \% & -14.1 \% & -10.9 \%\end{array}$

LAY = latest available year; North America (2009), Latin America (2009) and NonLatin Caribbean (2008).

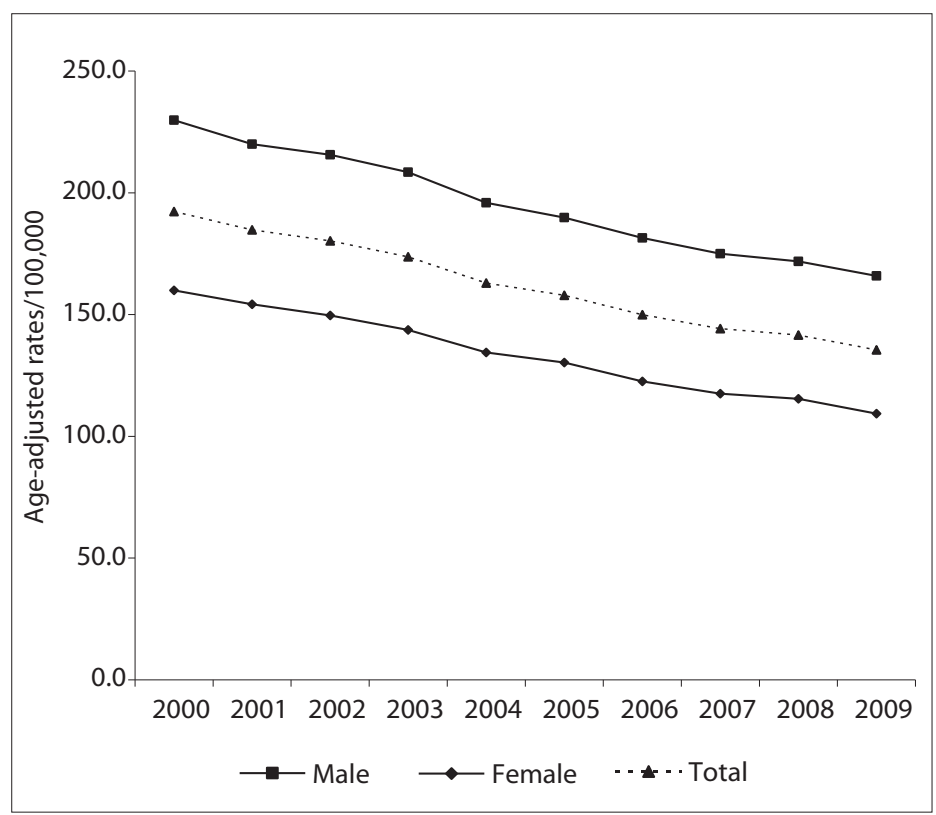

Figure 1. Trends in mortality due to cardiovascular diseases (ICD-10 100-199) (age-adjusted rates/100,000), in selected countries in North America (Canada and the USA), 2000-2009. 
deaths, its age-adjusted rates were the highest. The trend curves for males and females followed the same pattern as shown by the total population curve (Figures 1, 2 and 3).

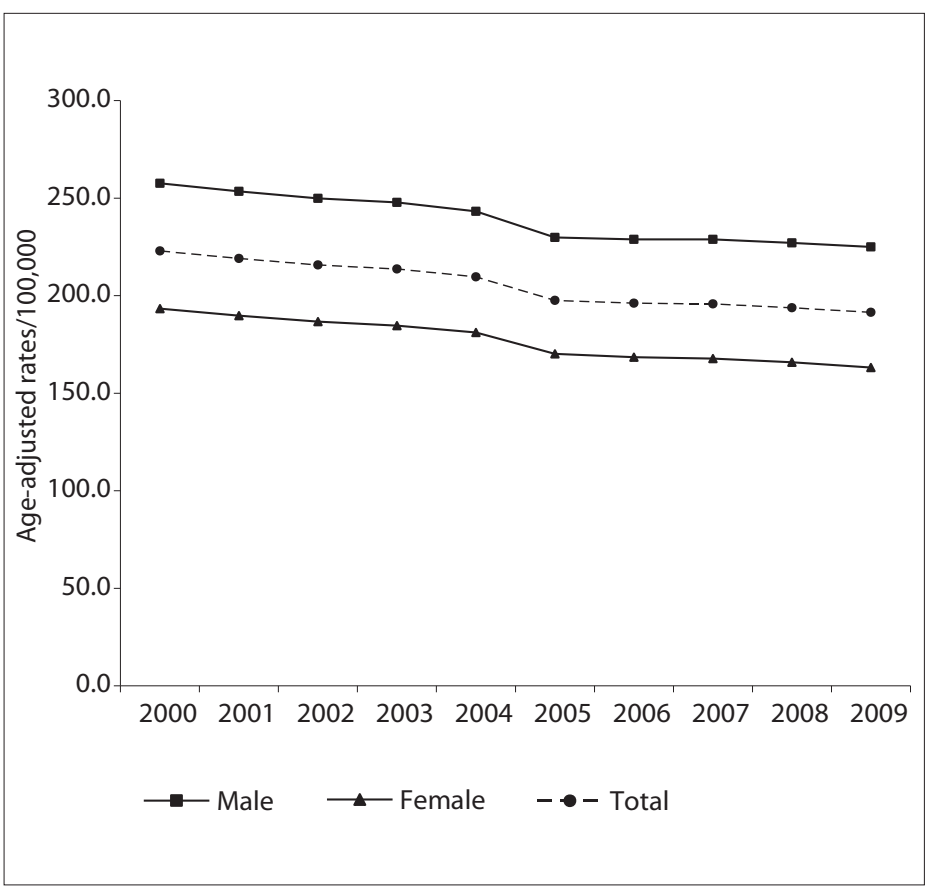

Figure 2. Trends in mortality due to cardiovascular diseases (ICD-10 I00-199) (age-adjusted rates/100,000), in selected countries in Latin America, 2000-2009.

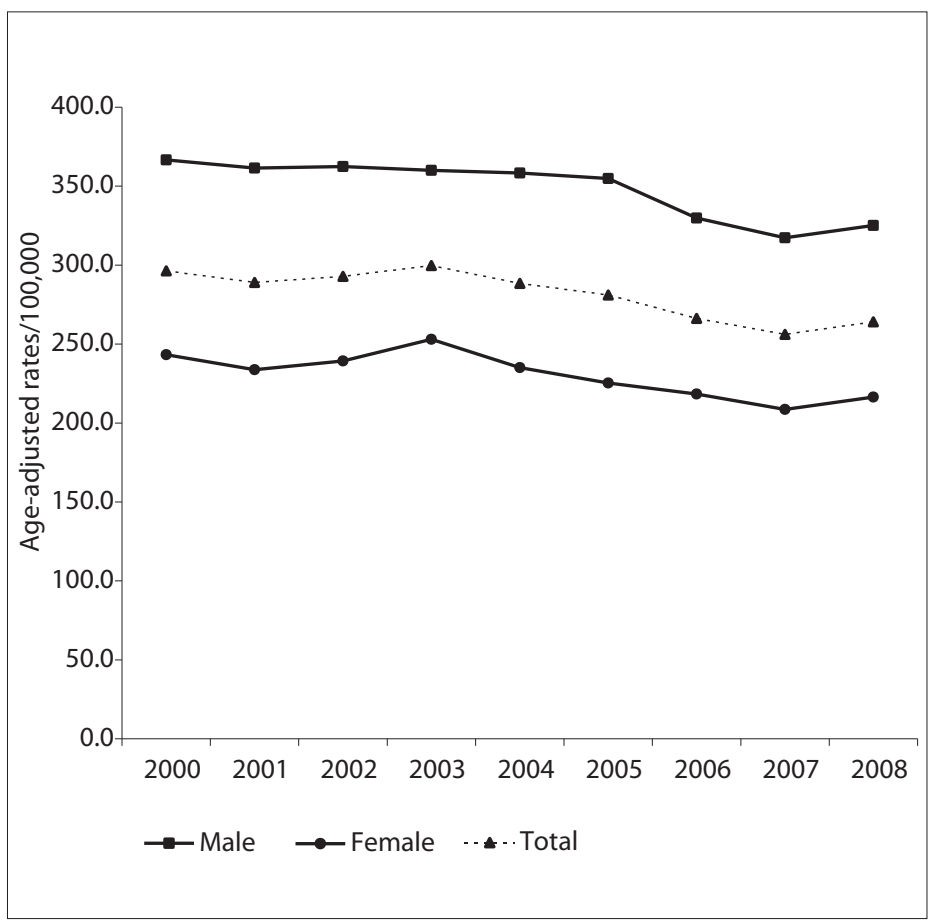

Figure 3. Trends in mortality due to cardiovascular diseases (ICD-10 I00-199) (age-adjusted rates/100,000), in selected countries in NonLatin Caribbean, 2000-2008.
The results from the joinpoint analysis (Table 2) showed that CVD mortality in North America declined significantly from 2000 to 2009 and the corresponding AAPC was $-3.9 \%(-4.3 \%$ among females and $-3.7 \%$ among males). In Latin America, the AAPC was $-1.8 \%$ over the entire period $(-2.0 \%$ among females and $-1.6 \%$ among males). In the Non-Latin Caribbean, the AAPC from 2004 to 2008 (the last 5 observations) was $-1.8 \%$ (-1.8\% among females and $-1.8 \%$ among males).

\section{DISCUSSION}

Our findings showed that mortality due to CVD has been decreasing in the three regions of the Americas, which is consistent with previous studies. ${ }^{4-8}$ However, there were marked differences among these regions. The North American countries, which have more favorable socioeconomic indicators, ${ }^{9}$ showed lower mortality rates, lower proportions of premature mortality and higher declines, in comparison with the selected countries in Latin American and the Non-Latin Caribbean.

The question that arises is what the reasons might be for the differences in the decline of CVD mortality. In Canada and the USA, mortality rates peaked in the mid-1960s and then experienced a long term decline. ${ }^{4,5}$ In the USA, approximately half of the decline in coronary disease mortality from 1980 to 2000 was attributable to clinical treatment (revascularization, initial treatment for acute myocardial infarction or angina and

Table 2. Joinpoint analysis for cardiovascular diseases (ICD10 100-199), according to sex and region. North America, Latin America and Non-Latin Caribbean, 2000-LAY

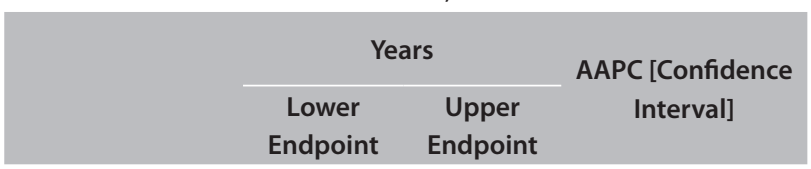

Total

$\begin{array}{llll}\text { North America } & 2000 & 2009 & -3.9^{*}[-4.2 ;-3.7] \\ \begin{array}{l}\text { Latin America } \\ \text { Non-Latin }\end{array} & 2000 & 2009 & -1.8^{*}[-2.2 ;-1.5] \\ \text { Caribbean } & 2004 & 2008 & -1.8^{*}[-2.7 ;-0.9]\end{array}$

Female

$\begin{array}{llll}\text { North America } & 2000 & 2009 & -4.3^{*}[-4.5 ;-4.0] \\ \begin{array}{l}\text { Latin America } \\ \text { Non-Latin }\end{array} & 2000 & 2009 & -2.0^{*}[-2.4 ;-1.6] \\ \begin{array}{l}\text { Caribbean } \\ \text { Cab }\end{array} & 2004 & 2008 & -1.8^{*}[-3.0 ;-0.7]\end{array}$

Male

$\begin{array}{llll}\text { North America } & 2000 & 2009 & -3.7^{*}[-3.9 ;-3.4] \\ \text { Latin America } & 2000 & 2009 & -1.6^{*}[-2.0 ;-1.3] \\ \begin{array}{l}\text { Non-Latin } \\ \text { Caribbean }\end{array} & 2004 & 2008 & -1.8^{*}[-2.6 ;-1.0]\end{array}$

$\mathrm{LAY}=$ last available year; ${ }^{*}$ The AAPC (average annual percentage change) is significantly different from "zero" at alpha $=0.05$. 
other treatments) and approximately half to changes in risk factors (reductions in total cholesterol, blood pressure, smoking and physical inactivity). ${ }^{15}$ For some Latin America countries for which published trend series studies are available, the decline took place recently, or there was no decline or even an increase. ${ }^{4-5,8}$ These countries have probably implemented community-based prevention programs more recently.

In addition, populations that live in countries with more disadvantaged incomes might face greater difficulties in obtaining access to treatment, compared with those who live in North American countries. Some countries in the Americas, such as Argentina, Brazil, Cuba and Canada, have public universal health coverage. Despite this, in Brazil, a study found that premature mortality due to circulatory system diseases was 2.6 times higher in poor areas in Porto Alegre than in rich areas. ${ }^{16}$ In São Paulo, the decline in the risk of death due to heart disease was faster for people living in the wealthiest areas and slower for people living in lower-resourced neighborhoods. ${ }^{17}$ In the United States, which has a different health system and the percentage health insurance coverage is around $83 \%$, a study showed racial disparities in use of coronary artery bypass grafting and percutaneous transluminal coronary angioplasty among elderly women and men, which was probably due to access to care and financial barriers. ${ }^{18}$

Regarding risk factors, a lot of work has to be done in the region. In the USA, around $90 \%$ of the people consume sodium at levels above the recommended guidelines. ${ }^{19}$ The prevalence of an abnormally large abdominal waist circumference among people aged 20 years and over was around $70 \%$ in San Salvador, El Salvador (52\% among males and 79\% among females), and $64 \%$ in Belize (20\% among the white population and 63\% among the black and mixed population). ${ }^{20}$ In Brazil, the prevalence of medical diagnoses of hypertension among the adult population reached $23 \%$ in 2010 (26\% among females and $21 \%$ among males). ${ }^{21}$ On the positive side, prevention activities have been implemented in many countries. Argentina, Barbados, Bolivia, Brazil, Chile, Cuba, Dominica, Mexico, Panama and Venezuela have implemented CVD and hypertension control programs. ${ }^{22}$ Tobacco policies have been implemented in 13 countries in Latin America. Mexico, Brazil, Chile, Costa Rica, Dominica, Paraguay and Peru have implemented initiatives to regulate the marketing of foods to children. ${ }^{23}$

It should be noted that the CVD burden goes beyond mortality. It has social and economic impacts such as increased costs of healthcare, disabilities and losses in productive years of life due to premature mortality. For example, in the United States, the estimated cost of medical care for CVDs in 2009 was around US\$ 314 billion, and the indirect costs due to disability and deaths was around US $\$ 161$ billion, which raised the total cost of these diseases to US\$ 475 billion. ${ }^{23}$

The main limitations of the present study are the following: 1) although the rates were corrected for under-registration of deaths and ill-defined causes, it is possible that these problems might affect the rates in some countries, especially those with lower resources; and 2) some lower-resourced countries have made efforts to improve the quality of data, including decreasing the numbers of ill-defined deaths, which might lead to an increase in circulatory system disease rates.

Since disease is a great contributor to poverty, the Americas should strive to bridge the gap in treatment and preventive control of CVD among its regions. Gold-standard prevention requires complementary clinical and community approaches and monitoring information regarding mortality, morbidity and prevalence of risk factors. Eliminating health disparities should be a goal in relation to CVD mortality reduction in the region.

\section{CONCLUSION}

Mortality rates due to CVD have been decreasing since 2000 in the North American, Latin American and Non-Latin Caribbean regions. Disparities in risk, premature mortality and trends were seen across these three different regions.

\section{REFERENCES}

1. Ordúñez García P, Campillo Artero C. Regional Consultation. Priorities for cardiovascular health in the Americas. Key messages for policymakers. Washington: Pan-American Health Organization; 2011 Available from: http://www1.paho.org/priorities/pdf-en/book.pdf. Accessed in 2013 (May 23).

2. Mendis S, Puska P, Norrving B. Global Atlas on cardiovascular disease prevention and control. Geneva: World Health Organization; 2011. Available from: http://whqlibdoc.who.int/ publications/2011/9789241564373_eng.pdf. Accessed in 2013 (May 23).

3. Newschaffer CJ, Longjian L, Sim A. Cardiovascular diseases. In: Remington PL, Brownson RC, Wegner MV, eds. Chronic disease epidemiology and control. Washington: American Public Health Association; 2010. p. 383-428.

4. Mirzaei M, Truswell R, Taylor, Leeder SR. Coronary heart disease epidemics: not all the same. Heart. 2009;95(9):740-6.

5. Rodríguez T, Malvezzi M, Chatenoud L, et al. Trends in mortality from coronary heart and cerebrovascular diseases in the Americas: 19702000. Heart. 2006;92(4):453-60.

6. Schmidt MI, Duncan BB, Azevedo e Silva G, et al. Chronic noncommunicable diseases in Brazil: burden and current challenges. Lancet. 2011;377(9781):1949-61. 
7. Frieden TR; Centers for Disease Control and Prevention (CDC). Forward: CDC Health Disparities and Inequalities Report - United States, 2011. MMWR Surveill Summ. 2011;60 Suppl:1-2.

8. de Fatima Marinho de Souza M, Gawryszewski VP, Orduñez P, Sanhueza A, Espinal MA. Cardiovascular disease mortality in the Americas: current trends and disparities. Heart. 2012;98(16):1207-12.

9. Ahmad OB, Boschi-Pinto C, Lopez AD, et al. Age standardization of rates: a new WHO standard. GPE Discussion Paper Series: No. 31. World Health Organization 2001. Available from: http://www.who. int/healthinfo/paper31.pdf. Accessed in 2013 (May 23).

10. Pan American Health Organization. Health situation in the Americas: basic indicators 2012. Washington: Pan American Health Organization; 2012. Available from: http://ais.paho.org/chi/ brochures/2012/BI_2012_ENG.pdf. Accessed in 2013 (May 23).

11. Health Organization. WHO Discussion Paper: A comprehensive global monitoring framework and voluntary global targets for the prevention and control of NCDs. Available from: http://www.who. int/nmh/events/2011/consultation_dec_2011/WHO_Discussion_ Paper_FINAL.pdf. Accessed in 2013 (May 23).

12. Organización Panamericana de la Salud. Organización Mundial de la Salud. Estadísticas de salud de las Américas. Edición 2006. Available from: http:www.paho.org/ESA2006. Accessed in 2013 (May 23).

13. United Nations, Department of Economic and Social Affairs, Population Division. World population prospects: The 2010 Revision, Highlights and Advance Tables. New York: United Nations; 2011. Available from: http://esa.un.org/wpp/documentation/pdf/ WPP2010_Highlights.pdf. Accessed in 2013 (May 23).

14. Clegg LX, Hankey BF, Tiwari R, Feuer EJ, Edwards BK. Estimating average annual per cent change in trend analysis. Stat Med. 2009:28(29):3670-82.

15. Ford ES, Ajani UA, Croft JB, et al. Explaining the decrease in U.S. deaths from coronary disease, 1980-2000. N Engl J Med. 2007;356(23):2388-98.

16. Bassanesi SL, Azambuja MI, Achutti A. Premature mortality due to cardiovascular disease and social inequalities in Porto Alegre: from evidence to action. Arq Bras Cardiol. 2008;90(6):370-9.

17. Lotufo PA, Fernandes TG, Bando DH, Alencar AP, Benseñor IM. Income and heart disease mortality trends in Sao Paulo, Brazil, 1996 to 2010. Int J Cardiol. 2012;6. [Epub ahead of print].

18. Gillum RF. Coronary revascularization in older women and men in the United States: trends in ethnic differences. Am Heart J. 2004;147(3):418-24

19. Centers for Disease Control and Prevention (CDC). Million hearts: strategies to reduce the prevalence of leading cardiovascular disease risk factors--United States, 2011. MMWR Morb Mortal Wkly Rep. 2011;60(36):1248-51.

20. Organización Panamericana de la Salud. Iniciativa Centro Americana de Diabetes (CAMDI). Encuesta de diabetes, hipertensión y factores de riesgo de enfermedades crónicas. Tegucigalpa, Honduras; 2009.
Available from: http://www.paho.org/hon/?cx=01428377084524 0200164\%3A4igtso_4aue\&q=Encuesta+de+diabetes\%2C+hipert ensión+y+factores+de+riesgo+de+enfermedades+crónicas\&sea rchword=Encuesta+de+diabetes\%2C+hipertensión+y+factores+ de+riesgo+de+enfermedades+crónicas\&sa=Buscar...\&cof=FORID \%3A0\&searchphrase=all\&ie=iso-8859-1\&scope=1\&option=com_ search\&ltemid=1\&siteurl=www. paho.org\%2Fhon\%2F\&ref=www. paho.org\%2F\&ss=32j1024j2\#gsc.tab=0\&gsc.q=encuesta\%20 diabete\&gsc.page $=1$. Accessed in 2013 (May 23).

21. Brasil. Ministério da Saúde. Secretaria de Vigilância em Saúde. Secretaria de Gestão Estratégica e Participativa. Vigitel Brasil 2010: vigilância de fatores de risco e proteção para doenças crônicas por inquérito telefônico. Brasília: Ministério da Saúde; 2011. Available from: http://portal.saude.gov.br/portal/arquivos/pdf/vigitel_2010_ preliminar_web.pdf. Accessed in 2013 (May 23)

22. Pan-American Health Organization. Non communicable diseases project \& Health information and analysis project \& Sustainable development and environment area. Non communicable diseases in the Americas: Basic indicators on non communicable diseases, 2011. Washington; 2011.

23. Labarthe DR. Cardiovascular diseases: a global public health challenge. In: Labarthe DR. Epidemiology and prevention of cardiovascular diseases: a global challenge. $2^{\text {nd }}$ edition. Massachusetts: Jones and Bartlett Publishers; 2011. p. 3-18. Available from: http://samples. jbpub.com/9780763746896/46894_fm_00i_xviii.pdf. Accessed in 2013 (May 23).

\section{Sources of funding: None}

Conflicts of interest: None

Date of first submission: September 25, 2012

Last received: June 18, 2013

Accepted: July 5, 2013

\section{Address for correspondence:}

Vilma Pinheiro Gawryszewski

Health Analysis and Information Project

Pan-American Health Organization

$52523^{\text {rd }}$ St.

Washington DC 20037

United States

Tel. 202-492-7492

Fax. 202-974-3674

E-mail: gawry@uol.com.br, gawryszv@paho.org 